\title{
Testing Weak Form of Efficient Market Hypothesis: Empirical Evidence for Bullions and Base Metal Segment of Indian Commodity Market
}

\author{
Suresh K Mittal and Mohan Thakral*
}

Haryana School of Business, Guru Jambheshwar University of Science and Technology, Hisar-125001, Haryana, India

*Corresponding author: mohanthakral@gmail.com

\begin{abstract}
With the advent of higher level of trading in commodities, investors' focus has moved towards commodity market in recent years. Efficiency of the markets is the main area of concern for market players and always considered a valuable addition to the body of knowledge on investment management. Among all the commodities traded in Indian commodity market, bullions and base metals have emerged as a bigger area of interest for the investors. Industrial usage of these commodities with their participation in individual's investor portfolio as an investment avenue, increases their relative importance among other commodities. This paper examines the weak-form of Efficient Market Hypothesis (EMH) for both the segments. The period of study is 8 years, commencing from 2009, daily spot prices of commodities have been used to test the market efficiency in weak form. The weak form efficiency is thoroughly scrutinized with the help of graphs, runs test, augmented dicker fully and variance ratio test. The results of all the tests deployed in the study are consistent with each other and confirms the weak-form inefficient behavior of bullions and base metals.
\end{abstract}

Keywords: Commodity Market, Market Efficiency, Runs test, Augmented Dicker Fully test, Variance Ratio

The efficient markets hypothesis (EMH), widely known as the Random Walk Theory, states that current stock prices fully reflect available information about the value of the underlying assets which implies investor can not earn excess return by using this information. The concept of "efficient market" was first coined by E.F. Fama. According to Fama (1991), instant absorption of any new information in the actual prices of securities shows the level of efficiency in the market. Indian commodity market behaves randomly (weak form efficient) or the returns can be predicted with the help of past information (weak form inefficient) is an area of great interest for the investor due to the rapid development in Indian commodity market. An investor has numerous investment options to choose from bullion, gold and silver are promising options among the various investment alternatives available to the investor. The low volatility of gold prices judged against to equity market, fluctuating nature of Indian rupee against US Dollar and mounting uncertainty about global economy increased the importance of gold as a strong investment asset class. Indeed, gold and silver perceived as a monetary instrument, as a financial asset, and as a raw material primarily used in jewelry and ornamental substances. As an asset, gold classically is viewed as a shock absorber asset during times of political, social, and economic distress. Importance of base metal in metallurgy sciences with history dating back to $6000 \mathrm{BC}$ is known to all. There are more than 85 different types of metals are available to mankind. The Indian metal industry, endowed with huge amount of natural resources in the form of mineral deposits. With larger investments by Indian firms and technical advancement hammering in, 
outputs of the industry and quality of the products have increased significantly. Growing inclination of investors towards the said commodities necessitates the need to examine the market efficiency of these commodities. This study is an attempt in this regard and also attempts to find out the validity and applicability of weak form efficiency of bullions and base metals segments for generating abnormal returns.

\section{LITERATURE REVIEW}

Capital market efficiency implies that assets prices respond instantaneously and precisely to the relevant information. As information arrive the asset prices must also behave or fluctuate.

Fama (1970) in his work "Efficient Capital Markets: A review of theory and empirical work" stated that a market is said to be efficient if not even a single investor has competitive advantage as far as right to use to information and deployment of that information is concerned. Andrew and Mathew (2002) studied the "Market Efficiency in Agricultural Future Markets" in four agricultural commodity futures (Livecattle, hogs, corn, soybean) were examined in the study. Results confirmed the efficiency in live cattle, hogs, corn and soy bean meal futures markets, and biased in the long run, also suggest short run time varying risk premium in cattle and hogs futures markets.

Ahuja (2006) recommended, the market based mechanism rather than administrated price mechanism in commodities derivatives. The study also observed that removal of government protection from several commodities leads to the market growth in terms of technology, transparency and trading activity. Hence, market based mechanism is the best possible solution for the efficiency of market.

Lokare (2007) observed the increasing level of commodities, but with uneven level of progress with respect to liquidity. To achieve economy of scale and reduced transaction cost additional amount of liquidity is required in case of some commodities. The study confirmed the dawdling rate of development either in case of operational efficiency or market efficiency. Study suggested that wealthy resources, infrastructure and policy reforms can be the key for the development of commodities market. Easwaran and Ramasundaram (2008) examined the market efficiency of four commodities (castor, cotton, pepper and soya) traded on MCX and NCDEX platform of Indian commodity market, study rejected the presence of market efficiency in selected commodities.

Hazen and Shrestha (2008) examined the stock market index of UAE to test the efficiency of the market in weak-form. Results of the unit root tests models confirmed that the stock markets of UAE follow random walk. Vashishtha and Kumar (2010) suggested that due to unique features of derivatives like risk transfer and price discovery, derivatives have altered the landscape of financial industry. India's experience with the start of equity derivatives market has been enormously cheering and successful. The derivatives turnover on the NSE has surpassed the equity market turnover. Appreciably, its growth in the recent years has surpassed the growth of its matching part globally. Kashif et al. (2010) examined the stock market efficiency of 14 Asian stock markets including China and Japan. Results of autocorrelation, Runs test, Unit root test and the Variance ratio concluded that monthly prices don't follow a random walk and consequently the stock markets are inefficient at the weak-level. Abdullah (2012) studied random walk theory in the Saudi stock exchange. Linear serial dependence had been found as a result of Autocorrelation along with the runs test. Thus, Saudi stock market found to be inefficient at the weak level. As above-mentioned studies, the analysis of the previous literatures revealed mix results about the efficiency. What is more, the review of prior empirical evidences raised some research question: Is the Indian commodity as an emerging market weak-form efficient or not?

\section{Objective of the study}

The main objective of the study is to examine the weak form of efficient market hypothesis on various commodities; gold, copper, lead, zinc aluminum, nickel, and silver considered as prime commodities traded in Indian commodity market. Gold and silver traded under the bullion segment whereas remaining commodities are traded under the banner of base metal. 


\section{Research Methodology}

The study under consideration Testing Weak Form of Efficient Market Hypothesis: Empirical Evidence for Bullions and Base metal segment of Indian Commodity Market has been conducted to examine the weak form of market efficiency of commodities traded under bullions and base metal segment of Indian commodity market. The study is conducted in an empirical format confined to secondary data only.

\section{Hypothesis}

In order to examine the market efficiency in weak form, historical sequence of commodity prices are studied for randomness to test the following null hypothesis:

$\square \mathrm{HO}_{1}$ : Successive commodity price movement's pattern is identical to that of random numbers.

$\square \mathrm{HO}_{2}$ : Return series of commodity prices behavior is not stationary.

\section{Sample Size and Sources of Data}

For the purpose of analysis and testing the weak form efficiency spot prices of gold, copper, lead, zinc aluminum, nickel, and silver have been collected from the website of MCX. The data used for the study is ranging from March 1, 2009 to December 31, 2016.

\section{Statistical Tools}

The present study on Testing Weak Form of Efficient Market Hypothesis: Empirical Evidence for Bullions and Base metal segment of Indian Commodity Market has been conducted by using Runs Test, Augmented Dicker Fuller test and Variance Ratio test.

\section{Runs Test}

Runs test, is one of the primary tests used to check the randomness of the data. Basically Runs Test measures the total number of runs in a data and then compares them with the expected number of runs. The test is designed to examine whether successive price changes are independent. The test is based on the premise that if a series of a data is random, the observed number of runs in the series should be close to the expected number of runs.
A run refers to a continuum of either positive or negative movements. Suppose if + is used to depict a positive movement, then a streak of these positive signs (+) constitutes a run. The formula used for calculating the expected runs and variance of the data is given below:

$\mathrm{Z}=\mathrm{R}-\mathrm{E}(\mathrm{r}) /$ St. Dev.

Where, $\mathrm{R}=$ Total number of runs observed

Expected Runs $(\mathrm{R})=2 \mathrm{~N} 0 . \mathrm{N} 1+1 / \mathrm{N} 1+\mathrm{N} 0$

$\mathrm{N} 1$ = Number of positive runs

$\mathrm{N} 0=$ Number of negative runs

Variance: 2N1.N0 (2N1.N0-N1-N0)/ (N1 + N0) ${ }^{2}$

$(\mathrm{N} 1+\mathrm{N} 0-1)$

\section{Augmented Dickey-Fuller Unit Root Test}

Unit Root Test: Unit root test can be applied for testing the efficiency of markets. A efficient market need to be in the random form because market efficiency demands randomness in the daily returns of commodities and unit root test investigates whether the time series is non stationary or not. If the test statistic is more negative or smaller than the critical value (Mackinnon tabulated value) then the null hypotheses will be rejected which means data is not non stationary. In this study Augmented Dickey-fuller test has been considered for test of unit root The Augmented Dickey-Fuller (ADF) consist of estimating following regression equation:

$$
\Delta Y_{t}=\beta_{1}+\beta_{2} t+\delta Y_{t-1}+\sum_{i=1}^{m} \alpha_{i} \Delta Y_{t-1}+\varepsilon_{t}
$$

\section{Variance Ratio Test}

Variance ratio test has been employed to examine the predictability of asset returns proposed by Lo and Mackinlay (1988). According to this test, variance of difference of time series has compared over dissimilar intervals. In a random walk of a time series, variance of $\mathrm{p}$ periods must be $\mathrm{p}$ times the variance of single period difference. Variance ratio test statistics are used to examine the random walk behavior of time series under homoskedastic and hetroskedastic assumption with the help of asymptotic distributional. This study has also employed multiple variance ratio test suggested by Chow and Denning (1993). Multiple ratio test is based upon the same approach as 
followed by variance ratio test, multiple ratio test provide the joint probability whereas variance ratio test bestowed with individual output of every interval. Multiple variance ratios have also been checked under homoskedastic and hetroskedastic assumption. According to multiple variance ratio test $p$-value of greater than 0.05 and a $Z$ value in the interval of $+/-1.96$ means that variance ratio (VR) of joint period is 1 , which lead to the acceptance of null hypothesis. Test criterions remain the same for the homoskedastic and hetroskedastic assumption.

\section{ANALYSIS AND DISCUSSION}

This section explains the analysis and findings of the study for the various statistical tools applied. Table 1 indicates the descriptive statistics of commodities under study.
Table 1 contains the descriptive statistics of all the commodities taken in the present study. The total no. of observations taken under the study are $2281,2194,1857,2286,2288,2199$ and 2270 for aluminum, copper, gold, lead, nickel, silver and zinc respectively. The mean value of daily return is maximum for Zinc (.0687) followed by Lead (0678), Copper (.0548), Silver (.0471), Gold (.0424), Nickel (.0310) and Aluminum (.0307), Whereas lead (4.070) shows the highest value of variance followed by nickel (3.867), zinc (3.352), copper (2.692), silver (2.455) and aluminum (1.706).

\section{Run Test}

Table 2 represents the results of runs test. The variable under study, like spot price in present study, must be divided into two groups on the

Table 1: Descriptive Statistics

\begin{tabular}{cccccccc}
\hline & $\mathbf{N}$ & Range & Minimum & Maximum & Mean & Std. Deviation & Variance \\
\hline Aluminum & 2281 & 14.11 & -7.23 & 6.88 & .0307 & 1.30601 & 1.706 \\
Copper & 2194 & 22.63 & -9.89 & 12.74 & .0548 & 1.64071 & 2.692 \\
Gold & 1857 & 14.37 & -8.37 & 6.00 & .0424 & .98346 & .967 \\
Lead & 2286 & 38.04 & -18.86 & 19.18 & .0678 & 2.01748 & 4.070 \\
Nickel & 2288 & 27.76 & -14.20 & 13.56 & .0310 & 1.96657 & 3.867 \\
Silver & 2199 & 27.20 & -15.31 & 11.89 & .0471 & 1.56678 & 2.455 \\
Zinc & 2270 & 33.34 & -16.87 & 16.47 & .0687 & 1.87932 & 3.532 \\
Valid N (listwise) & 1857 & & & & & & \\
\hline
\end{tabular}

Table 2: Runs Test: Cut-off Point is median

\begin{tabular}{cccccccc}
\hline & Aluminum & Copper & Gold & Lead & Nickel & Silver & Zinc \\
\hline Test Value & 106.35 & 393.10 & 26813.00 & 113.05 & 899.60 & 41654.00 & 106.55 \\
Cases $<$ Test Value & 1138 & 1097 & 929 & 1143 & 1143 & 1100 & 1135 \\
Cases $>=$ Test Value & 1144 & 1098 & 929 & 1144 & 1146 & 1100 & 1136 \\
Total Cases & 2282 & 2195 & 1858 & 2287 & 2289 & 2200 & 2271 \\
Number of Runs & 96 & 31 & 56 & 106 & 83 & 37 & 78 \\
Z & -43.802 & -45.581 & -40.564 & -43.441 & -44.425 & -45.379 & -44.433 \\
p-value & .000 & .000 & .000 & .000 & .000 & .000 & .000 \\
\hline \multicolumn{7}{c}{ Runs Test: Cut-off Point is mean } \\
\hline Test Value & Aluminum & Copper & Gold & Lead & Nickel & Silver & Zinc \\
\hline Cases $<$ Test Value & 104.2720 & 369.8993 & 24987.3724 & 111.3858 & 881.5337 & 41644.1300 & 110.1913 \\
Cases $>=$ Test Value & 886 & 935 & 622 & 1032 & 1013 & 1099 & 1308 \\
Total Cases & 1396 & 1260 & 1236 & 1255 & 1276 & 1101 & 963 \\
Number of Runs & 2282 & 2195 & 1858 & 2287 & 2289 & 2200 & 2271 \\
Z & 122 & 26 & 10 & 102 & 65 & 35 & 60 \\
P-value & -42.448 & -45.771 & -42.650 & -43.568 & -45.142 & -45.465 & -45.131 \\
\hline
\end{tabular}


basis of a cut point. The cut point is based upon some measures of central tendency or a custom value. Median and mean both can serve the purpose of cut point. In the present study, both median and mean have been considered as cut points. If $\mathrm{P}$-value is smaller than alpha i.e. 0.05, it means $Z$-value does not lies in between -1.96 to +1.96 which implies that prices of the commodity does not appears in random manner. And if P-value is greater than alpha i.e. 0.05 and Z-value does lies in between -1.96 to +1.96 , which means that prices of the commodities are random in nature. In the present study $\mathrm{p}$-value for all the commodities are less than 0.05 . In addition to that $Z$ value for all the commodities is not in between -1.96 to +1.96 . Hence, null hypothesis cannot be accepted that prices are randomly generated. Results of present study confirmed the weak form inefficient behavior of all the commodities for both the segments of commodity market.

\section{Unit Root test}

Table 3: Null Hypothesis: All the commodities has a unit root

\begin{tabular}{ccc}
\hline \multicolumn{3}{c}{ Exogenous: Constant } \\
\hline \multicolumn{3}{c}{$\begin{array}{c}\text { Table 3: Lag Length: 0 (Automatic - based on SIC, } \\
\text { maxlag = 25) }\end{array}$} \\
\hline Commodity & $\begin{array}{c}\text { Augmented Dickey- } \\
\text { Fuller test statistic }\end{array}$ & P-Value \\
\hline Aluminum & -54.26141 & 0.0001 \\
Copper & -54.32448 & 0.0001 \\
Gold & -32.6571 & 0.0000 \\
Lead & -55.22685 & 0.0001 \\
Nickel & -5.86387 & 0.0001 \\
Silver & -48.75392 & 0.0001 \\
Zinc & -58.42697 & 0.0001 \\
\hline
\end{tabular}

Test critical values:

Tabulated MacKinnon

(1996) one-sided

$-2.862655843$

p-values.

In this study augmented dickey-fuller test was chosen to test the unit root. For daily return series, if calculated ADF test statistic negatively go above from the MacKinnon tabulated value and p-value is also smaller than alpha (i.e. 0.05), leads to the rejection of null hypothesis. According to the ADF test null hypothesis assume that daily return series has a unit root. A series having unit root means it is non stationary in nature. Table 3 summarizes the findings of ADF test for all the commodities under study. Results for daily returns of various commodities concluded that P-value for all the commodities undertaken in the study is well below the .05 of alpha level. Furthermore, ADF test statistic for all the commodities negatively exceeds the MacKinnon tabulated value. So, we have to reject null hypothesis that daily return series contains unit root. In other words return series are stationary and does not exhibit randomness in nature.

\section{Variance ratio tests}

Table 4: Multiple Variance Ratio Test

\begin{tabular}{|c|c|c|c|c|}
\hline 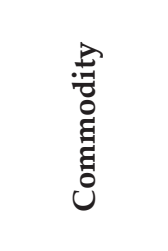 & 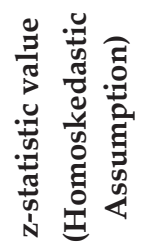 & 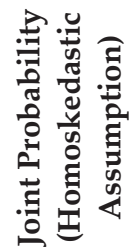 & 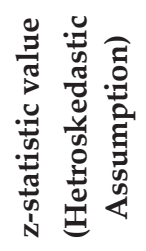 & 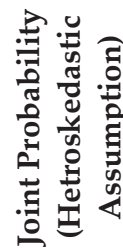 \\
\hline Alumnium & 26.9399 & 0.0000 & 13.68896 & 0.0000 \\
\hline Copper & 26.57674 & 0.0000 & 13.53473 & 0.0000 \\
\hline Gold & 19.47457 & 0.0000 & 9.225185 & 0.0000 \\
\hline Lead & 26.84503 & 0.0000 & 7.254317 & 0.0000 \\
\hline Nickel & 26.23197 & 0.0000 & 11.76232 & 0.0000 \\
\hline Silver & 24.31967 & 0.0000 & 8.191074 & 0.0000 \\
\hline Zinc & 28.08043 & 0.0000 & 8.393292 & 0.0000 \\
\hline
\end{tabular}

Table 5: Individual Variance ratio test Variance Ratio In Specified Legs

\begin{tabular}{ccccc}
\hline Period & $\mathbf{2}$ & $\mathbf{4}$ & $\mathbf{8}$ & $\mathbf{1 6}$ \\
\hline Alumnium & 0.43568 & 0.2173 & 0.11046 & 0.05786 \\
Copper & 0.43248 & 0.22711 & 0.10933 & 0.05221 \\
Gold & 0.54784 & 0.23711 & 0.12413 & 0.06319 \\
Lead & 0.43829 & 0.22017 & 0.10951 & 0.0553 \\
Nickel & 0.45123 & 0.22772 & 0.11816 & 0.05523 \\
Silver & 0.48115 & 0.23698 & 0.12102 & 0.06214 \\
Zinc & 0.41011 & 0.21043 & 0.10197 & 0.05205 \\
\hline
\end{tabular}

Table 4 and 5 reveals the result of multiple variance tests and individual ratio test. Table 4 shows the joint probability value under homoskedastic and hetroskedastic assumption by using asymptotic distributional. Z-statistic value for all the commodities taken under study: gold $\left(19.47457^{*}\right.$, $\left.9.225185^{* *}\right)$, copper $\left(26.57674^{*}, 13.53473^{* *}\right)$, lead $\left(26.84503^{*}, 7.254317^{* *}\right)$, zinc $\left(28.08043^{*}, 8.393292^{* *}\right)$ aluminum $\left(26.9399^{*}, 13.68896^{* *}\right)$, nickel $\left(26.23197^{*}\right.$, 
$\left.11.76232^{* *}\right)$, and silver $\left(24.31967^{*}, 8.191074^{* *}\right)$ showed Z-value outside the specified interval of $+/-1.96$, with a probability value of less than 0.05 . Hence we reject the null hypothesis and concluded that daily return series do not follow random walk. Results of individual period in table 5 also supplements the result of multiple variance tests, from the results of all the legs $(2,4,8,16)$, variance ratio is not equal to one for any commodity in any leg. According to existing literature if variance ratio is not equal to one then study has to reject the null hypothesis of random walk behavior. Plots of daily return series of all the commodities are also in consistency with the results of run tests and ADF test of the study. Graphical representation of the return series showed that returns does not follow the random walk model because returns are stationary. (* Z-Value under homoskedastic, ** Z-Value under hetroskedastic assumption).

\section{CONCLUSION}

According to literature a weak form efficient market should be free from any kind of dependency on the past returns of the market. Future returns of the market should be independent of past returns. Ultimate objective is to bring all the investors at same platform, no investor should have the scope to earn abnormal returns in a weak form efficient market. Purpose of the study was to examine the weak form market efficiency of bullions and metals. It has found that return series of all the commodities does not contain unit root. Absence of unit root point towards the stataionarity in the data, hence predictability is possible in calculating future returns. Outputs of run test also recommend that expected number of runs is not in accordance of actual number of runs, in variance ratio test under the assumptions of homoscedasticity vs heteroscedasticity, joint probability for all the

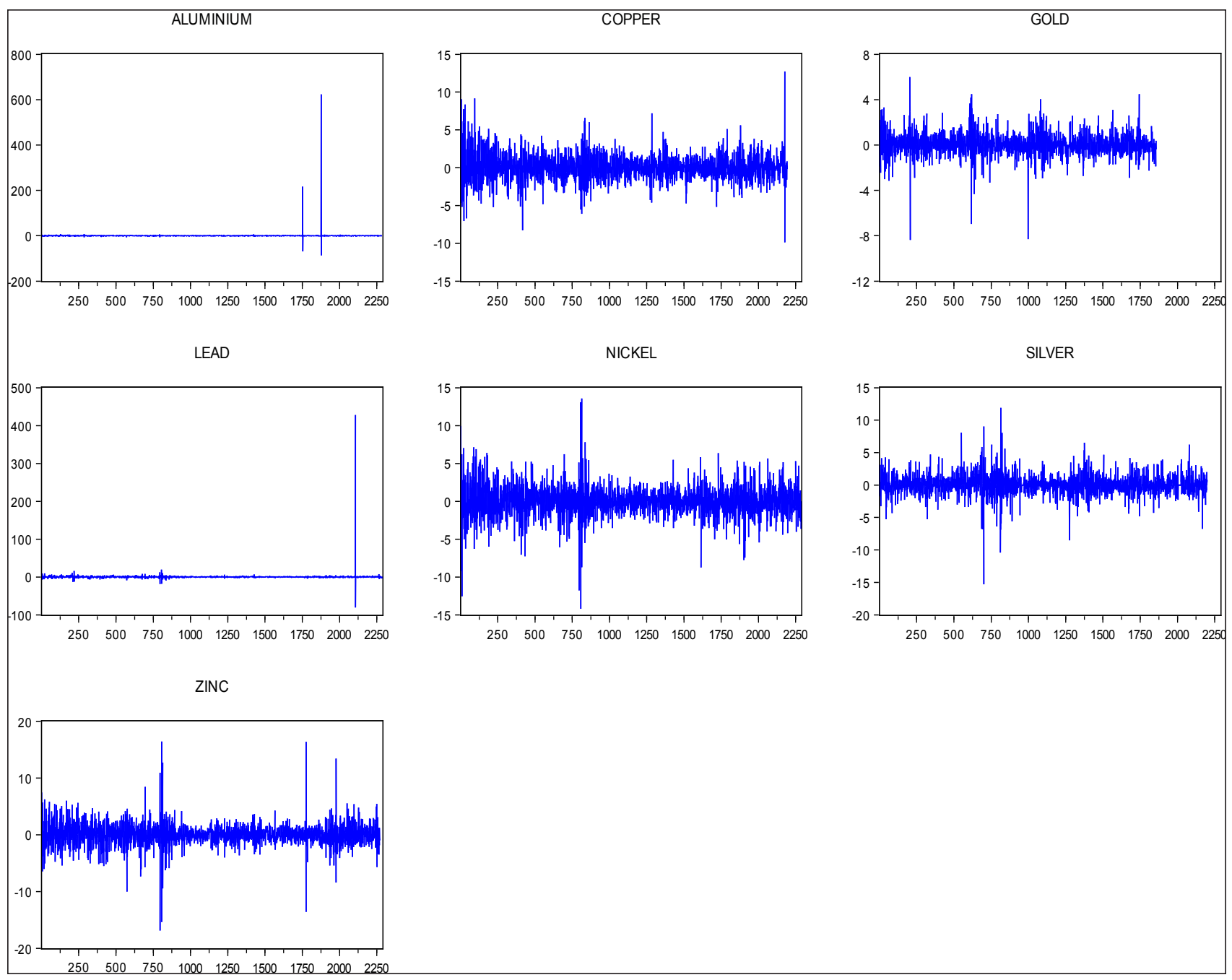

Fig. 1 
commodities is below than 0.05 , further variance ratio $\neq 1$ in any case, which discards the presence of randomness in data. Results of statistical tools (Augmented Dicker fully test, Run test and variance ratio test) concludes that Aluminum, Copper, Gold, Lead, Nickel, Silver and Zinc does not follow random walk.

\section{REFERENCES}

Abdullah, A. 2012. “Testing the weak form of efficient market hypothesis and the day- of- the- week effect in Saudi stock exchange", International Review of Business Research Papers, 8: 27-54.

Ahuja, L.N. 2006. "Commodity Derivatives Market in India: Development, Regulation and Future Prospects", International Research Journal of Finance and Economics, 2: 1450-2887.

Andrew, M.A. and Mathew, H. 2002. "Market efficiency in agricultural futures markets", Applied Economics, Taylor $\mathcal{E}$ Francis Journals, 34(12): 1519-1532.
Easwaran, R.S. and Ramasundaram, P. 2008. "Whether Commodity Futures Market in Agriculture is Efficient in Price Discovery?-An Econometric Analysis", Agricultural Economics Research Review, 21: 337-344.

Fama, E. 1970. “Efficient capital markets: A review of theory and empirical work", The Journal of Finance, 25(2): 383-417.

Fama, E. 1991. “Efficient capital markets-II: A", The Journal of Finance, 46(5): 1575-1617.

Hazen, M. and Shrestha, B. 2008. “European Journal of Economics, Finance and Administrative Sciences, 12.

Kashif, H. et al. 2010. "Testing the weak form of efficient market hypothesis: empirical evidence from Asia-pacific markets", International Research Journal of Finance and Economics, 58: 122-133.

Lokare, S.M. 2007. “Commodity Derivatives and Price Risk Management: An Empirical Anecdote from India", Reserve Bank of India Occasional Papers, 28: 02.

Vashishtha, A. and Kumar, S. 2010. “Development of Financial Derivatives Market in India- A Case Study", International Research Journal of Finance and Economics, 37: 1450-2887. 
